The INL is a

U.S. Department of Energy

National Laboratory

operated by

Battelle Energy Alliance

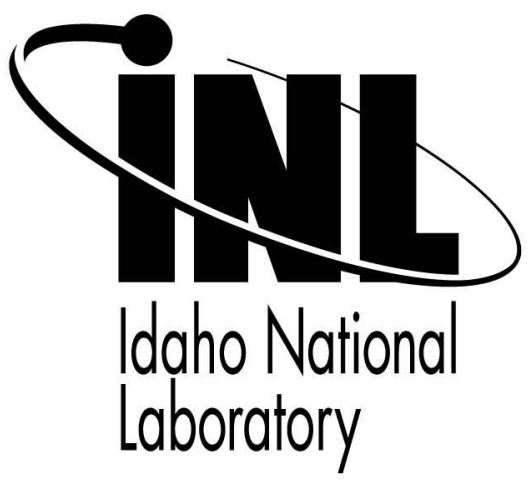

\section{Issues for Conceptual Design of AFCF and CFTC LWR Spent Fuel Separations Influencing Next-Generation Aqueous Fuel Reprocessing}

\section{Global 2007, International Conference on Advanced Nuclear Fuels Cycles and Systems}

D. Hebditch

R. Henry

M. Goff

K. Pasamehmetoglu

D. Ostby

\section{September 2007}

This is a preprint of a paper intended for publication in a journal or proceedings. Since changes may be made before publication, this preprint should not be cited or reproduced without permission of the author. This document was prepared as an account of work sponsored by an agency of the United States Government. Neither the United States Government nor any agency thereof, or any of their employees, makes any warranty, expressed or implied, or assumes any legal liability or responsibility for any third party's use, or the results of such use, of any information, apparatus, product or process disclosed in this report, or represents that its use by such third party would not infringe privately owned rights. The views expressed in this paper are not necessarily those of the United States Government or the sponsoring agency. 
Global 2007, Int. Conf. on Advanced Nuclear Fuels Cycles and Systems, Boise, Idaho, USA, Sept 9-13, 2007

\title{
ISSUES FOR CONCEPTUAL DESIGN OF AFCF AND CFTC LWR SPENT FUEL SEPARATIONS INFLUENCING NEXT-GENERATION AQUEOUS FUEL REPROCESSING
}

\author{
D. Hebditch, R. Henry, M. Goff, K. Pasamehmetoglu and D. Ostby \\ Idaho National Laboratory, P.O. Box 1625, Idaho Falls, ID 83415, U.S.A; David.Hebditch@inl.gov
}

\begin{abstract}
In 2007, the U.S. Department of Energy (DOE) published the Global Nuclear Energy Partnership (GNEP) strategic plan, which aims to meet US and international energy, safeguards, fuel supply and environmental needs by harnessing national laboratory $R \& D$, deployment by industry and use of international partnerships. Initially, two industryled commercial scale facilities, an advanced burner reactor (ABR) and a consolidated fuel treatment center (CFTC), and one developmental facility, an advanced fuel cycle facility (AFCF) are proposed. The national laboratories will lead the AFCF to provide an internationally recognized RD\&D center of excellence for developing transmutation fuels and targets and advancing fuel cycle reprocessing technology using aqueous and molten salt methods. The design drivers for AFCF and CFTC LWR spent fuel separations are expected to impact on and reflect those for industry, which is engaging with DOE in studies for CFTC and ABR through the GNEP funding opportunity announcement (FOA). The paper summarizes the state-ofthe-art of aqueous reprocessing, assesses engineering drivers for U.S. aqueous processing facilities, examines historic plant capital costs and provides conclusions with a view to influencing design of next-generation fuel reprocessing plants.
\end{abstract}

\section{INTRODUCTION}

Under GNEP strategy, ${ }^{1}$ the U.S. seeks cooperation to:

- Expand nuclear power to help meet growing energy demand in an environmentally sustainable manner.

- Deploy advanced technologies for recycling spent nuclear fuel (SNF) that avoid $\mathrm{Pu}$ separation and eventually eliminate excess stocks of civilian $\mathrm{Pu}$ and SNF. The technologies will reduce nuclear waste, simplify disposal, and enable the use of a single geologic repository in the U.S. in the $21^{\text {st }}$ century.

- Develop, demonstrate, and deploy advanced reactors to consume transuranic elements from recycled SNF.

- Establish supply arrangements among nations to provide reliable fuel services worldwide for generating nuclear energy, by providing nuclear fuel and taking back SNF for recycling, without spreading enrichment and reprocessing technologies.

- Deploy U.S. recycling facilities, led by industry, with technology support from DOE national laboratories, international partners, and universities.

- These facilities comprise an advanced fuel cycle facility (AFCF) for RD\&D, an advanced recycling reactor (aka ABR) to convert TRU into shorter-lived radioisotopes, while producing electricity and an SNF recycling center (aka CFTC) to deploy advanced separation and fabrication technologies.

DOE is currently funding AFCF conceptual design activities and CFTC scoping studies. The former is a comprehensive RD\&D facility with relatively small irradiated fuel throughput comprising LWR and ABR SNF receipt, reprocessing, ABR fuel re-fabrication and recycling, product storage, and waste immobilization and storage. The latter are preliminary studies relevant to commercial scale plant for LWR fuel reprocessing, ABR fuel material generation and storage, and waste immobilization and storage. For DOE, previously accomplished Engineering Alternative Studies (EAS) for LWR SNF separations provided a benchmark of advanced technologies for comparison of the GNEP FOA CFTC proposals. Both AFCF and CFTC meet the GNEP objectives for next-generation fuel cycles including substantial advancements in safeguards, material control and accountability (MC\&A), separations, fuel fabrication, and waste forms. AFCF conceptual design is currently at the $30 \%$ level and due for completion in late 2009 whilst CFTC EAS is a collection of scoping studies related to a commercial scale UREX+ reprocessing plant.

\section{COMMERCIAL LWR, FAST REACTOR AND ADVANCED FUEL REPROCESSING}

The state-of-the-art of commercial LWR fuel processing and developments in fast reactor (FR) reprocessing relevant to design are summarized since these form most of the building blocks for advanced fuel reprocessing. Nuclear fuel reprocessing flow-sheets and unit operations have undergone both progressive and stepwise improvements over the past $60+$ years to deal with new fuels and meet raised standards. RD\&D work on several of the major conceptual advancements now proposed, such as co-processing and minor actinide (MA) partitioning, commenced several decades ago. ${ }^{2,3,4}$ Separations equipment and facility design has developed to meet new requirements. The now "conventional" PUREX process for relatively high burn up oxide LWR fuel is exemplified by French (UP-2, UP-3), UK 
(THORP), ${ }^{5,6}$ and Japanese (Rokkasho) plants; the latter derived from French technology. These represent the current generation and industrial state-of-the-art. They are strongly linked to vitrification of HLW and its medium term passive storage. Plant approval, design, construction, and commissioning often took between one and two decades. They demonstrate that routine operation and commercial scale throughput is fully feasible following the accumulation of significant know-how. Each plant represents a significant industrial achievement. The main world-wide functional characteristics of industrial LWR PUREX reprocessing may be summarized as:

- Providing pure $\mathrm{PuO}_{2}$ and $\mathrm{UO}_{2}$ products (subject to ingrowth in storage).

- $\quad \mathrm{FP}$ and minor actinides (Am, $\mathrm{Cm}, \sim 50 \%$ of $\mathrm{Np}$ ) are immobilized by vitrification.

- Cladding wastes, including undissolved fuel residues, are compacted or cemented for deep disposal.

- Liquid wastes (with $\mathrm{Np}$ ) concentrated for recycle to vitrification or treated for sea discharge (with ${ }^{3} \mathrm{H}$ ).

- Off-gases treated (C, I, NOx, dust, etc. removal) for discharge to atmosphere (with ${ }^{85} \mathrm{Kr}, \mathrm{Xe}$ ).

- Fabrication of MOX $\left(\mathrm{U}_{-} \mathrm{PuO}_{2}\right) \mathrm{LWR}$ fuel for recycle.

- Improved recoveries, reduced discharges, and lower worker and world doses c.f. earlier generation plants.

- Natural convection air-cooled stores for vitrified waste (50-100 a) for heat decay storage.

These plants use multiple-pin shears (vertical cut of intact LWR assemblies without inert gas - UK, and horizontal cut on a batch of disassembled pins with $\mathrm{N}_{2}$ inerting - France), single type dissolver (batch or continuous capable of moderate leaching of hulls), centrifugation of dissolver liquor, solvent extraction separations plant using pulse columns for high active (HA) and Pu purification cycles, and mixer settlers for some U streams and solvent wash. For THORP, the shear is within a shear cave with extensive routine remote refurbishment capabilities for the shear pack. Remote operations occur within the dissolver cell, but the batch dissolvers are not routinely replaceable. French technology makes use of continuous dissolvers with moving and replaceable parts requiring remote maintenance. Relatively compact "dark cells" are used for solvent extraction with equipment designed for full plant lifetime and little planned remote intervention, drives external to cells, use of constant volume feeders and pneumatically driven fluidic transfers, and avoidance of valves for active liquor. There is removal of $\sim 99 \%$ of activity in the first cycle, an early split of $\mathrm{U} / \mathrm{Pu}$ using $\mathrm{U}^{\mathrm{IV}}$ reduction of $\mathrm{Pu}$, cycle(s) of $\mathrm{U}$ purification with thermal denitration to pure $\mathrm{UO}_{3}$ product, and cycle(s) of $\mathrm{Pu}$ purification with thermal decomposition of oxalate to pure $\mathrm{PuO}_{2}$ product (mixed oxide; Rokkasho). Where maintenance of active plant is required, it is now normally fully remotely cleaned and dismantled. These plants are an extension of earlier French and UK plants operated for lower burn-up metallic fuels, which were based on mixer settler technology. The change to pulse columns was for criticality safety and solvent stability issues. The adoption of centrifugal contactors was considered by some but would have needed greater change in design philosophy, and experience, and taking on full remote maintenance.

In the 1970s, U.S. design studies were performed for several large-scale LWR commercial reprocessing plants; two used design approaches similar to those discussed above, although with shielded bulges for infrequently decontaminated/maintained equipment, ${ }^{7,8}$ whilst another, ${ }^{9,10}$ used a more conservative approach related to that of remote canyons built at Savannah River in the 1950's for highly flexible application of defense separations. ${ }^{11}$ Each canyon has two long open process areas known as the hot and warm canyons, placed on either side of a central services corridor. The remote bridge crane brings active fuel feed and exchanges or revises equipment as required. In general, three main cell concepts can be identified: (1) Canyon, with essentially complete flexibility for operating/ process recovery and change; (2) Remotely maintained hot cell, where cell and equipment are optimized at outset and most moderate scale equipment items are replaceable but the process may not be; and (3) Dark cell, where items are designed for full plant life and zero maintenance/ change is planned. A variant of the shielded bulge/ segregated cell concept with hands on maintenance is probably no longer viable due to lowered dose limits for commercial plants, but might be worth considering for demonstration plants. The AGNS Barnwell plant ${ }^{7}$ which has design parallels with THORP, was built but never operated actively.

For national strategic purposes, development work for FR plants continued in a number of countries up until the 1990s and then in fewer, though now increasing again. The ORNL Consolidated Fuel Reprocessing Program (CFRP) together with ANL has been influential in promoting the wider use of centrifugal contactors (favored due to high fissile content and decay power), associated remote handling systems and hardware representative of most unit operations in reprocessing conceptual designs. ${ }^{12,13,14}$ For remote maintenance, viewing and reach are important; typically equipment is rack mounted vertically on walls and uses guides to locate modules including base positioning pins and for smallmedium loads $(<100 \mathrm{~kg})$. Additionally, hoists and cranes may be required to supplement manipulators. Due to criticality safety requirements, the higher actinide content (and high burn up) of FR fuels strongly reduces single line throughputs, for example, an FR batch dissolver may be limited to a throughput of $\sim 0.2 \mathrm{t}(\mathrm{HM}) / \mathrm{d}$, as compared 
to $\sim 2.5 \mathrm{t}(\mathrm{HM}) / \mathrm{d}$ for a similar unit for LWR fuel. If full equipment remote replacement capability is required for an LWR plant, then much greater modularization, assembly/disassembly, and mechanical handling capability may be needed. The low throughput, materials transfer, and batch nature of current electrometallurgical processing of FR fuel already suits a fully remotely maintained approach. ${ }^{15}$ Due to high Pu contents, FR oxide fuel development emphasized concerns over fuel dissolution residues and alternative reagents and processes for enhanced dissolution, including secondary leach units, which are now relevant to the high recovery aims of the U.S. advanced fuel cycle, as outlined below.

Besides other goals, advanced fuel cycles generally seek to partition medium and long-lived radioactive species in SNF and wastes, and optimize paths for transmutation, decay storage, and immobilization and disposal to reduce potential environmental impacts. The U.S. advanced fuel cycle stems from the GNEP strategy ${ }^{1}$ as exemplified by UREX+ flow-sheets developed under full active, bench-scale conditions by ANL et al. under AFCI and GNEP programs. ${ }^{16}$ DOE may consider industry investment proposals for initial commercial implementation, which may differ from $\mathrm{UREX}^{+}$, but still meet GNEP requirements and not produce pure $\mathrm{Pu}$. A suite of UREX+ flow-sheets provides for the separation of LWR SNF constituents by aqueous solvent extraction to produce a variety of products, by-products, and wastes to meet specifications for recycle, HLW or Class C disposal. Five process segments separate SNF into seven (or more) streams: (1) Iodine for safe disposal; (2) Tc for safe disposal; (3) $\mathrm{U}_{3} \mathrm{O}_{8}$ for recycle or disposal as LLW; (4) Cs$\mathrm{Sr}$ for storage for decay heat reduction; (5) $\mathrm{Np}-\mathrm{Pu}$ for mixed oxide fuel for thermal or fast reactor recycle; (6) $\mathrm{Am}-\mathrm{Cm}$ for ABR irradiation; and (7) residual fission products for deep repository disposal. Essentially all $U$ and most Tc is removed at the first step, then Cs-Sr, followed by mixed TRU (or Pu-Np), MAs, and finally mixed FPs. Fuel dissolution is preceded by a voloxidation stage to recover volatiles such as krypton, xenon, tritium, and iodine, and enhance dissolution. The effectiveness of the UREX+ based advanced fuel cycle relies on relatively high U product purity, high recoveries of actinides, and good purity of Cs-Sr by-product. Separations and transmutation criteria and effect on repository utilization are presented. ${ }^{17}$ The AFCF will perform demonstration and development of several UREX+ flow-sheets, baseline UREX+1a with LWR and ALWR, and then later ABR fuels and the CFTC EAS scopes a UREX+1a baseline for LWR fuels processing for comparison with industry proposals. The AFCF will also demonstrate recycle of ABR fuels using the U.S. electrorefining process; an advanced method due to its avoidance of pure Pu product, integral recycle of MA, and suitability to high fissile content, high burn up, short cooled fuels. As presently developed for metal fuels, it does not reduce the early heat load of HLW in the disposal repository.

In addition to the U.S., the main countries in which advanced fuel cycle work is being performed are Japan, France, and the Russian Federation (R.F.). As may be expected, the emphases and objectives vary. Japan has both accelerator and partitioning and FR reprocessing development activities. JAEA has a strong emphasis on FR economics, including cost and process optimization of the FR fuel cycle. Four favored options, simplified PUREX, dry oxide electrowinning, dry metallic electrorefining, and dry fluoride volatilization, were examined in detail. This led to the selection of a simplified advanced aqueous reprocessing system integrated with a simplified pelletizing remote fuel fabrication system, which provides removal of the majority of uranium by crystallization, co-extraction of low $\mathrm{DF}$ U-Pu-Np followed by other minor actinide recovery by extraction chromatography for FR recycle. ${ }^{18}$ It forms a near conventional HLLW (ex MA) for vitrification with high early decay power and reduced long term decay heat, and contains some long-lived FPs with potential for mobility under some repository conditions. Japan continues to study pyrochemical processes.

For commercial LWR fuel reprocessing at Cap La Hague in France, AREVA has been successful in significantly reducing the overall volume of HLW and introducing centrifugal contactors to the $\mathrm{R} 4 \mathrm{Pu}$ finishing facility. Based on extensive work since the 30 December 1991 Act, CEA and CNRS have developed chemical and hydrometallurgical techniques for extraction of a wide range of radioactive species. The COEX process is an extension of PUREX to produce mixed $\mathrm{Pu}-\mathrm{U}(-\mathrm{Np})$ and pure $\mathrm{U}$ products probably by partial U-Pu partitioning and by raising acidity in the first cycle to increase coextraction of $\mathrm{Np}$ and reduce its loss to HA raffinate. More extensive partitioning has been developed for an "end of pipeline" approach where HA raffinate is treated by the DIAMEX process to separate MA and Ln from FPs, followed by the SANEX process to separate MAs from lanthanides, the SESAME process to separately recover $\mathrm{Am}$ and $\mathrm{Cm}$, and the use of Calixarenes to separate Cs from the residual FP stream (after which Ln is returned to FPs for vitrification) ${ }^{19,20}$ Recovery of MA from existing vitrified HLW is excluded. Recent R\&D work proposes the GANEX concept for early partial (majority) separation of $\mathrm{UO}_{2}{ }^{2+}$ by means of a monoamide selective extractant, followed by co-extraction of all remaining actinides. ${ }^{21}$ CEA continues to research pyrochemical methods, particularly for transmutation fuels and targets.

The R.F. plans to increase thermal reactor capacity and construct $\mathrm{BN}$-type fast reactors. An advanced fuel cycle will be demonstrated using a pilot complex of BN- 
800, RIAR, and Mayak. From existing stores or aqueous reprocessing plant, $\mathrm{Pu} / \mathrm{PuO}_{2}$ will be provided to a molten salt, electrowinning plant integrated with a module for vibropacking $\mathrm{MOX} /(\mathrm{U}-\mathrm{PuN})$ fuel for BN/BREST FRs. Irradiated FR fuel will be recycled using the RIAR DDP method. Longer term aims are to minimize recycle cost and waste volumes, avoid use of pure fissile materials and complete homogeneous recycle of MA. ${ }^{22,23}$

\section{DESIGN ISSUES}

The role of the AFCF is that of a research technology development, and demonstration facility. It will provide information on costs, safety, safeguards, security, and design basis for commercial scale reprocessing plants and be available to trouble-shoot and/or optimize production operations. It will also provide advanced fuel, lead test assemblies (LTA) of potentially oxide, metallic, nitride pellet and particle variants, to the ABR for transmutation fuel qualification. Commencing operation in the 2020s, it will provide flexible RD\&D capabilities for the following half century of nuclear fuel cycle support. Some thirty issues, which are important for conceptual design of AFCF and commercial scale advanced fuel processing plants, such as shown by CFTC EAS and related AFCF design studies, are given in Fig. 1 and discussed below under the six sectors shown. Various trade studies have been performed, are in progress, or are planned.

\section{III.A. GNEP Leadership}

As part of GNEP, AFCF is intended to be the world's foremost facility for nuclear fuel cycle research, technology development, and demonstration. The facility will also support the near-term mission to develop and demonstrate technology in support of fuel cycle needs identified by industry, and the long-term mission to regain and retain U.S. leadership in fuel cycle operations. AFCF will demonstrate a more proliferation-resistant fuel cycle and make long-term improvements in fuel cycle effectiveness, performance, and economy.

\section{Feed \& Product}

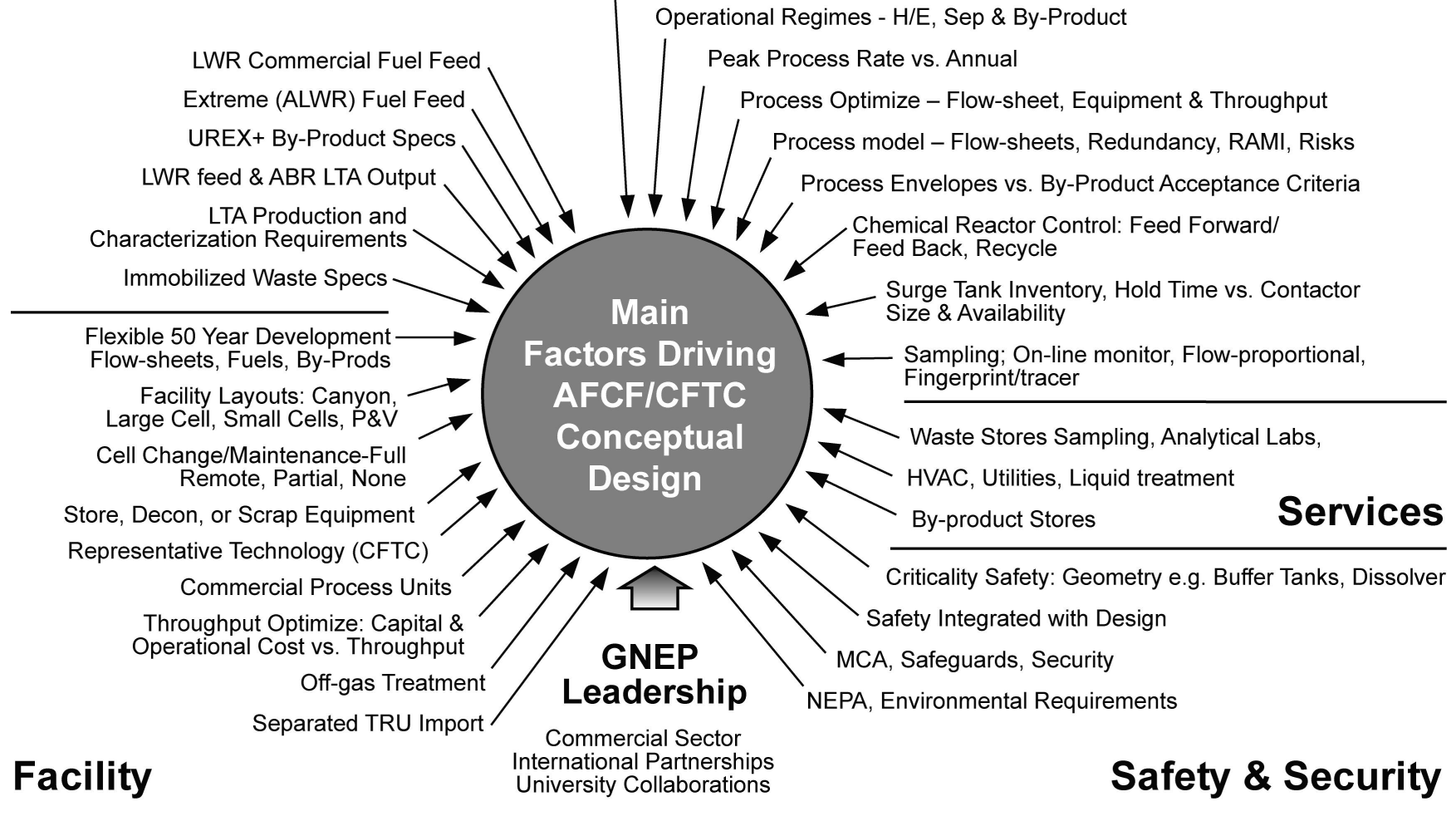

Fig. 1. Schematic of Drivers for AFCF/CFTC Conceptual Design.

\section{III.B. Feeds, Products, By-Products, and Wastes}

AFCF will obtain its initial supply of SNF from existing domestic PWR stocks to provide transuranic materials for fabricating LTAs for the ABR. After this, as
AFCF continues to expand its development reprocessing role, other feeds may be considered. Fuel data up until 2002 shows that most of the fuel discharged from U.S. PWRs has a burn-up $>25 \mathrm{GW}(\mathrm{t}) \cdot \mathrm{d} / \mathrm{t}(\mathrm{iHM})$ and $<60$ $\mathrm{GW}(\mathrm{t}) \cdot \mathrm{d} / \mathrm{t}(\mathrm{iHM})$; all has initial enrichment $\leq 5 \%{ }^{235} \mathrm{U}$. 
Studies are being performed on a median feed of 40 $\mathrm{GW}(\mathrm{t}) \cdot \mathrm{d} / \mathrm{t}(\mathrm{iHM})$ with a decay time of 10 years, which meets the reasonable criterion of minimum $\mathrm{Pu}$ fraction of total process fuel heavy metal of $\geq 1 \%$ to reduce the amount of fuel to be processed to extract required actinides for LTAs to be used in the ABR. Extremes of $100 \mathrm{GW}(\mathrm{t}) \cdot \mathrm{d} / \mathrm{t}(\mathrm{iHM})$ for ALWR and $25 \mathrm{GW}(\mathrm{t}) \cdot \mathrm{d} / \mathrm{t}(\mathrm{iHM})$ at 5 years (routine transport limitation) and 60 years cooling are being examined to define impacts on AFCF flow-sheets (radionuclide and elemental impacts through AMUSE code UREX+1a and UREX+4 modeling), criticality safety and source terms for radiolysis, shielding, and dose assessment. The highest LWR fuel burn-up value now proposed for future utility use is 100 $\mathrm{GW}(\mathrm{t}) . \mathrm{d} / \mathrm{t}(\mathrm{iHM})$, initial enrichment $<10 \%{ }^{235} \mathrm{U}$, although no current fuel has been irradiated beyond 63 $\mathrm{GW}(\mathrm{t}) . \mathrm{d} / \mathrm{t}(\mathrm{iHM})$ burn-up. Design excludes continuous feed of LWR fuel which has not been irradiated, has burnup histories less than $25 \mathrm{GW}(\mathrm{t}) . \mathrm{d} / \mathrm{t}(\mathrm{iHM})$, or is MOX. Eventually, irradiated ABR LTAs will be recycled to $\mathrm{AFCF}$ for reprocessing and re-fabrication by aqueous and/or molten salt methods.

The following target performance goals were drafted for aqueous separations:

1. U product recovery from SNF of $>99.9 \% \mathrm{wt}$.

2. Recovered $\mathrm{U}$ complies with Class $\mathrm{C}$ waste (nearsurface disposal) quantitative criteria (10CFR61.55).

3. Tc by-product recovery from SNF of $>99 \%$ wt.

4. Tc by-product shall contain $<0.1 \%$ wt. of $\mathrm{U}$.

5. Cs-Sr by-product recovery from SNF of $\geq 99 \%$ wt. of each of $\mathrm{Cs}$ and $\mathrm{Sr}$.

6. Composition of aged Cs-Sr by-product complies with Class C waste quantitative criteria (10CFR61.55).

7. Final TRU product of $>99.5 \%$ wt. of each of $\mathrm{Pu}, \mathrm{Np}$, and Am from SNF.

8. Purity of $\mathrm{Pu} / \mathrm{Np} / \mathrm{Am} / \mathrm{Cm}$ product to meet $\mathrm{Ln}$ impurity limits, in definition, for ABR fuel fabrication.

9. FP by-products to have, in aggregate, $<0.5 \%$ wt. of each of $\mathrm{Pu}, \mathrm{Np}$, and $\mathrm{Am}$ in SNF. Tc, Cs and $\mathrm{Sr}$ in FP wastes, in aggregate, each $<1 \%$ wt. of value in SNF.

10. Recovery, decay storage, and/or immobilization of $\geq$ $99 \%$ by wt. of ${ }^{3} \mathrm{H}$ in SNF.

11. Recovery, decay storage, and/or immobilization of $\geq$ $99 \%$ wt. of longer lived gaseous/ volatile radioisotopes including ${ }^{85} \mathrm{Kr},{ }^{14} \mathrm{C}$ and ${ }^{131} \mathrm{I}$ in SNF.

12. Undissolved solids from dissolution shall be $<1 \% \mathrm{wt}$. of initial HM oxide, and meet other goals listed here.

13. Operations shall be optimized to enhance security, safeguards, safety, and throughput capability.

The main components following UREX+ processing are given in Fig. 2 for a typical PWR SNF fuel assembly in the U.S. today based on $460 \mathrm{~kg}(\mathrm{U})$ initial enriched uranium, and $141 \mathrm{~kg}$ cladding and structural material.

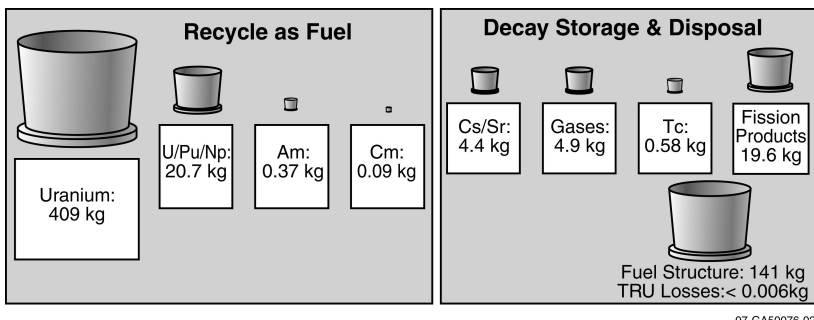

Fig. 2. UREX+ Flow-sheet Components of PWR Fuel.

Relative to commercial PUREX operations, the UREX+ process seeks more intensive leaching of hulls and minimal undissolved fuel solids. The uranium product purity is not exceptional but may be increased, if required, with an additional extraction cycle(s). The number and purities of various UREX+ by-product streams has never been accomplished on a production scale. The TRU recovery is higher than historically required. In contrast to commercial PUREX, all radioactive waste streams are captured and, for AFCF, are solidified to eliminate liquid radioactive discharges. Also, the AFCF requirement is that all wastes shall be treated, immobilized and stored as appropriate on an early timescale. For example, there will be no extended storage of HLLW. Immobilization occurs as soon as feed is available and interim storage is provided to accommodate down time for minor maintenance and repair of solidification equipment. A design issue is that of selecting commercial equipment or scaling down to the low AFCF throughput. The UREX+ process calls for the immobilization of the majority of fission products by vitrification, Tc alloyed by melting in a metal waste form, $\mathrm{Cs}-\mathrm{Sr}$ in a aluminosilicate generated by steam reforming, volatiles by adsorption/disposal (I, C, tritium), and noble gases ( $\mathrm{Kr}$, and possibly $\mathrm{Xe})$ decay stored in cylinders.

\section{III.C. Facility Characteristics and Equipment}

As the envisioned stand alone facility, AFCF has a wide range of processes, each with many unit operations, essentially replicating the whole back end of the advanced nuclear fuel cycle apart from disposal. Initially, AFCF will incorporate an integrated engineering scale processing system for an advanced LWR reprocessing technology, at a scale expected to be in the range 5-30 $\mathrm{t}(\mathrm{HM}) / \mathrm{a}$, to provide material feed for and perform remote fabrication of $\sim 4-10 \mathrm{LTA} / \mathrm{a}(\equiv 0.4-1 \mathrm{t}(\mathrm{HM} / \mathrm{a})$ and targets, and later to reprocess irradiated ABR fuel at $\sim 1 \mathrm{t}(\mathrm{HM}) / \mathrm{a}$. The initial reference LWR separations technology, UREX+1a, may evolve to another advanced set of technologies depending on industry and international partner inputs. By this means and later studies, AFCF will provide critical information for the design of future commercial production facilities. As such, the need for use of representative technology is important especially 
where this impacts on overall facility design. For security, safety, and other reasons, many of the structures and processing buildings are set below grade. The requirements to receive, store, shear, and remotely fabricate actual LWR fuel elements set the basic scale and arrangement of the facility. This led to design using two main process buildings for segregation of incompatible processes, e.g. aqueous and molten salt processing, with below ground tunnels for active material transfers, a building for solid products formation, and byproducts/wastes immobilization and a number of service buildings, e.g. HVAC provision. There are distributed control rooms for each major process/facility and a central command and control center may be needed. The current design philosophy utilizes dedicated suites of hot cells based on the process logic rather than using several large, tall cells where modular equipment for an entire process may be flexibly assembled on fit-together frames as required. The former provides better operational flexibility for each sub-process and segregation in case of releases to cell. For a given UREX+ flow-sheet, the facility footprint is more influenced by the space required for decoupling the various separations systems and their solidification processes than the space needed for increased throughput. UREX $+1 \mathrm{a}$ is the basis for the initial equipment design while $\mathrm{UREX}+4 \mathrm{a}$ is used to bound the largest facility. More evaluation of facility design for the lower end of the throughput range is likely concerning the impact of placing more processes in one structure and not having so many individual buildings with their own separate BOP utility needs. Simplifying wet and dry fuel receipt and storage facilities in favor of dry only, as suited to the sodium fast reactor, is under examination. This may possibly be extended by using $\mathrm{Nu}$-Holms type storage so that it could feed or discharge out the back directly into a remotely controlled dry SNF transfer system, which would transfer SNF to the head-end treatment system.

For low throughput, fuel dismantling and single or multiple-pin shearing is best suited. Shearing and voloxidation may share an inerted cell. For commercial scale, a continuous dissolver unit is most suitable, eg. French rotary unit. This capacity is excessive for AFCF throughput and other dissolver concepts, e.g. cascade type, are under consideration, which could provide more process flexibility and still provide continuous feed for separations. The desired high recoveries may call for separate oxidized fuel, hulls, and residues dissolution. Use of centrifugal contactors is specified for most of the active aqueous separations in AFCF whereas other types, such as mixer-settlers, may be used for solvent washing. The formation of solid products follows commercial practice in that thermal de-nitration is used for converting dissolved $\mathrm{UO}_{2}\left(\mathrm{NO}_{3}\right)_{2}$ to $\mathrm{UO}_{3}$ and thermal decomposition of precipitated oxalates, e.g. $\mathrm{Pu}\left(\mathrm{C}_{2} \mathrm{O}_{4}\right)_{2}$, to TRU oxides. By-products are immobilized using a range of processes including vitrification, steam reforming, and cementation. It is expected that commercially proven units will be used, which would then need low utilization. Waste stores are a significant cost item so that after completion of early LTA needs, the objectives and scope of demonstration campaigns should be optimized.

At the engineering throughput scale of 5-30 t(HM)/a, relatively small centrifugal contactors (e.g. commercial units of $5 \mathrm{~cm}$ or $12.5 \mathrm{~cm}$ rotor o.d.), pumps, and valves are needed, and full remote capability for maintenance and for complete equipment replacement for new processes within a single cell is technically and economically feasible as demonstrated by, for example, the ORNL CFRP experience. The main issue is that of criticality safe in-process liquor storage between process segments. Groups of tanks are housed in separate cells and not remotely replaceable. For medium values in the above throughput range, the aqueous separations cell size is dominated by vessel dimensions and numbers. One approach for AFCF as a long term reprocessing developmental facility is to provide extensive criticality safe tankage (numbers, type, and capacity) permanently installed in a series of cells. There could be a separate remotely maintained manifold, pump, and valve corridor with a view to flexible re-configuration of tankage by remote connectors. Contactors, cleaning units, and instrumentation may be installed in a further remotely maintained cell. Selection between several diverse layouts is required with iteration on the required throughput since the cell size and remote replacement time is sensitive to tank, contactor, and manipulator types. The canyon approach of independence from equipment design may not be necessary although flexibility is highly valued in a development facility. The UREX+1a flow-sheet has a maximum volumetric flowrate in one solvent extraction segment - TRUEX (MA-Ln recovery), that is around three times that of CCD-PEG (Cs-Sr separation). This suggests that differing diameter centrifugal contactors or parallel chains of same size be specified for different segments, which impacts on I\&C, cleaning, and maintenance. For a demonstration facility, it may be preferable to have two throughput requirements; the first being a conservative annual throughput that can be depended on for LTA material production, and the second a shorter term "sprint" rate for a period of, say, 2-4 weeks. Currently, the throughput rate and facility cost appear to be dominated by sizing the correct amount of surge capacity between separation process segments. The AFCF project may also evaluate the equipment design and UREX+ flow-sheet specification for a $2 \mathrm{t}(\mathrm{HM}) / \mathrm{a} A B R$ fuel reprocessing line. The very high TRU content, e.g $20 \%$ wt. ABR vs. $\sim 2 \%$ wt. in irradiated LWR, and high specific activity may require significant dilution, perhaps consistent with use of centrifugal contactors suited to $\mathrm{UREX}+$ processing of 5-10 $\mathrm{t}(\mathrm{HM}) / \mathrm{a}$ LWR fuel. If so, it 
may be better to run LWR processing for longer and reduce later equipment change for ABR fuel reprocessing.

Some design drivers favor a larger AFCF LWR SNF annual throughput, e.g. use of representative technology and/or commercial units, continuous operations, timeliness of producing materials for LTAs, support for commercial plant development, adequate waste production rates for development purposes, and flexibility for future fuel cycle and technology developments. Other drivers may point to a lower annual throughput, for example, capital cost, buffer storage between separation areas, TRU and waste storage requirements, criticality safety, and safeguards acceptability. Currently, it appears that the capital cost of AFCF is weakly sensitive to LWR SNF throughput in the range $10-30 \mathrm{t}(\mathrm{HM}) / \mathrm{a}$. Better understanding of this is a key factor including the aqueous reprocessing cell layout and size, buffer storage requirement, centrifugal contactor throughput capability, and remote maintenance capability. Throughput risk for LTA material production and flexibility for short periods of significant scale reprocessing development campaigns are the two main factors, which argue against reduction of the design basis throughput at least until an improved knowledge of relative capital cost versus throughput is established.

CFTC EAS investigated features of a canyon approach for a commercial scale reprocessing plant, with expected throughput of $\sim 3,000 \mathrm{t}(\mathrm{HM}) / \mathrm{a}$, with three solvent extraction lines. Many individual process components are substantial, e.g. shear, dissolvers, contactors, and process tanks. Criticality safety for buffer storage of UREX+ process liquor between separation process segments is ensured by administrative control. For a plant operating in the commercial sector, a dedicated shear and inert gas purged voloxidation cell for "dusty" LWR oxide fuel may be applicable before fuel feed to dissolution in a canyon. Dynamic modeling based on SRS historical reliability factors, etc, and estimated maintenance times applied to all steps has been used to estimate plant availability and throughput. Using the remote canyon approach, Savannah River has achieved high throughput for various non-commercial fuels using chemical de-cladding or total dissolution and showed handling and revision of large components. ${ }^{11}$ Flexibility of a canyon for complete equipment replacement is gained from standardization and precision of all wall and contact point placements. For a commercial facility, this degree of maintenance capability may not be necessary since the process will be known, less feed and process flexibility is normal, and the plant, if well specified and commissioned, should require few active piping or vessel modifications. Replacing part of the canyon concept, since this may be significantly increasing the processing footprint, with a combination of "pump \& valve corridor" and "dark cells" to reduce building size is possible. The canyon concept is not currently used for commercial PUREX reprocessing, due perhaps partly to differing European practice and also expected higher capital cost.

A CFTC follow-on EAS evaluation is likely to assume a smaller plant throughput $(\sim 800 \quad \mathrm{t}(\mathrm{HM}) / \mathrm{a}$ UREX+) with re-examination of facility layout options, requirements, etc. It may be worth examining a single line plant with throughput maximized within these constraints. The maximum contactor throughput/size should be broadly established and is expected to be criticality safety limited and flow-sheet dependent. Early PUREX plants for metallic fuels with low Pu content achieved single contactor line throughputs of greater than 1,000 t(HM)/a using administrative control for criticality safety. The LWR oxide plants of France and UK (and US Barnwell) use pulse columns in the diameter range $\sim 15-50 \mathrm{~cm}$, height 3-12 m, establishing a practicable criticality safety limited, upper throughput of $5 \mathrm{t}(\mathrm{HM}) / \mathrm{d} \equiv 800-1,000$ $\mathrm{t}(\mathrm{HM}) / \mathrm{a}$. Centrifugal contactors are likely to be in a similar diameter range but use a compact annular geometry, length to diameter ratio of 2-3, with air interface and flow through weirs. The safety case may assume that the contactor loses air and fills. Use of centrifugal contactors requires extensive remote maintenance capability and precludes installation in a dark cell.

\section{III.D. Safety, Safeguards and Security}

The AFCF shall be designed, constructed, and operated with emphasis on protection of public and worker safety and the environment. The AFCF Project will comply with Title 10 Code of Federal Regulations, Part 830, (Nuclear Safety Management), Subpart B (Safety Basis Requirements), and DOE Order 420.1B (Facility Safety), amongst other applicable legal requirements, standards, and guides. The project will comply with DOE-STD-1189-2006 (Integration of Safety into the Design Process), as drafted and finalized, during the conceptual design phase. Documented safety analyses will be developed in accordance with DOE Order 413.3 Project Management. The project safety system, structure, and component selection process will be implemented to meet current requirements and be flexible to support changing processes and requirements over the 50 years of operating lifetime. For criticality safety, DOE Order 420.1B and NRC Regulatory Guide 3.71 adopt more than a dozen American National Standards, which are relevant to AFCF operations and form the foundation of federal guidance in criticality safety. ANSI/ANS-8.1, Nuclear Criticality Safety in Operations with Fissionable Materials Outside Reactors, stipulates that operations shall be determined to be sub-critical for all normal and credible abnormal conditions. Two supporting recommendations are: (1) defense-in-depth, as embodied in the Double 
Contingency Principle, and (2) reliance on vessel dimensional control whenever practical. Where shielding and confinement protects personnel, ANS-8.10 allows reduced stringency where the consequences of criticality accidents are primarily damage to equipment, disruption of processes, spillage of product, contamination of facilities, etc. Future regulations may require that a probabilistic (quantitative) approach be adopted for "incredible" conditions. Issues of future concern are the developments in non-nuclear industry where inherent safety of processes is favored, nuclear reactor development where passive safety is emphasized, and the extent of incorporation of engineered methods for ensuring criticality safety. Minimization of fissile inventories in process and criticality analysis of designs to show the fission yield of most significant criticalities may be needed. Even for incidents where no human injury or environmental damage has occurred, risk of significant shut down of operations now stems from any perception by regulators and other stakeholders that the facility management has relinquished full control.

The AFCF safeguards and security function will meet DOE requirements for Category I special nuclear material including response to the 2005 DOE Design Basis Threat. There will be a Perimeter Intrusion Detection and Assessment System (PIDAS) at the Protected Area (PA) boundary. MC\&A will be consistent with DOE requirements, provide the current safeguards required for licensing, regulating, and/or monitoring the AFCF and develop advanced safeguards for licensing, regulating, and/or monitoring future full-scale commercial facilities. AFCF will develop and demonstrate advanced compliance methods meeting Nuclear Regulatory Commission (NRC) and International Atomic Energy Agency (IAEA) requirements. IAEA standards currently require the detection of diversion of one significant quantity (SQ), or $8 \mathrm{~kg}(\mathrm{Pu})$, per month which is difficult to achieve with current instrumentation at commercial plant scale. AFCF will undertake development of diverse advanced chemical and radioisotopic analysis and process instrumentation for accountancy and process monitoring.

Under the National Environmental Policy Act (NEPA), the GNEP Programmatic Environmental Impact Statement (PEIS) Report is covering the following scenarios: single greenfield facility and DOE brownfield split-sites facilities for $100 \mathrm{t}(\mathrm{HM}) / \mathrm{a}$ AFCF; and greenfield facility for 3,000 $\mathrm{t}(\mathrm{HM}) / \mathrm{a}$ CFTC EAS benchmark. NEPA studies are underway to analyze environmental impacts associated with the alternatives, provide technical information for the EIS, inform the public, and solicit public input and document selection of the final alternative for record of decision. Environmental permitting plans have been developed with generic site requirements for environmental monitoring, surface water protection, waste management permits and plans, wastewater treatment, air quality, and operational compliance activities. NEPA analysis defines the outer boundary within which the proposed action will occur. Safety analyses, then operating envelopes defined by facility design, and finally individual defined fuel cycle processes with bounding daily inventories provide a series of progressively tighter boundaries. Each level avoids challenge to the next higher level.

\section{III.E. Process Optimization}

As seen in section III.B, the AFCF has impressive separation goals for the advance fuel cycle, and will require a good operational strategy for the voloxidation and dissolver operations, solvent extraction campaigns, re-work needs, solid products formation, and by-products immobilization. The objective is that of providing an integrated engineering-scale system for fuel processing. Operational modeling may be needed to evaluate the optimal strategy from a range of possibilities including continuous operation, batch or short campaigns, effectiveness and throughput of fuel voloxidation and dissolution, and blending for rework of off-specification material. Evaporation and subsequent re-dilution may possibly be used to add surge capacity. There are a series of interdependent separations with many specified (by-) product streams with significant material accountability and need for integration of sampling and analysis capabilities. Knowledge of the optimum operating strategy is important to how the facility is designed. The high volume separations and solidification processes may possibly be operated continuously and those for the remaining low volume material in a batch manner. This may reduce the footprint and staffing, and obtain the desired processing rate from a moderate sized facility. The startup and re-start strategy for each solvent extraction segment is important to meeting process goals.

AFCF design and CFTC EAS scoping are considering incorporation of three types of dissolvers (main, residues, and hull leach), voloxidation unit, and inerted atmosphere shear. At least one of the operating commercial PUREX plants uses a single dissolver type air atmosphere shear and incorporates hulls washing/leaching as required. There may be potential to optimize the headend area to meet the TRU recovery requirement, etc. and reduce equipment costs and operational complexity.

In AFCF, buffer capacity is provided by criticality safe slab or pencil tanks to optimize plant throughput by decoupling separation segments. The buffer storage between separation areas is based on the assumed time for mixing, sampling, analysis, authorization, and connection for discharge following tank filling. The value is presently taken as 24 hours and investigation is underway of 
whether this value may be reduced. A single value will likely not suit all segments nor work for all circumstances. A reliability model may be needed to evaluate surge capacity issues throughout the plant. With better estimates for analytical results, maintenance, mass balance, MC\&A, etc., there will be a better appreciation of the needs for surge capacity (process decoupling) and/or parallel processing lines. For yearly throughput, a trade-off is expected between increased process rate (larger contactors) and increased process interruptions (smaller buffer storage). Design requires that one tank be filling, one emptying, one mixed and analyzed, and the last ready for discharge. Development work for substantial reduction of buffer storage requirements and associated operational improvements may be essential to effective commercial scale deployment. Fingerprint or tracer parameters may be identified for each UREX+ intermediate product to enable on-line monitoring. Flowproportional samplers may be used to gather liquor during tank filling and avoid time delay associated with mixing after filling followed by sampling.

AFCF is a development facility and may be less costly to oversize the contactor chain (larger diameter higher throughput) and develop operational improvements than to increase the buffer storage capacity. Use of some large, compact (non criticality-safe), off-line storage tanks is likely for materials, which have been characterized as safe but requiring re-work due to being outside byproduct specification. Modeling of the stability characteristics of the chemical flow-sheets, their margin between requirements and predicted values, and robustness to input and process transients may be needed. This will improve understanding of requirements for control of coupled processes. Normally, separations are operated by supply of active feed and reagents of known characteristics, flow rates, and temperature, i.e. feed forward control. There may be some possibilities for use of feedback and adaptive control, such as chemical reactor control where the desired product concentration is maintained through on-line monitoring and feed flows are controlled automatically. Some routine recycle of product stream, i.e. rework, may be used to damp the output of the system though at the price of increasing contactor flows.

The use of centrifugal contactors is valuable for operational flexibility due to rapidly reaching steady state, e.g. hours, as opposed to days for pulse column or mixersettler type. Utilization of centrifugal contactors enables stopping feed and discharge whilst allowing the contactors to continue spinning for some hours. A longer period, e.g. 24 hours, may be permissible if the first and last contactors remain spinning to retain phase separation for later initial discharge and the intermediate ones are stopped to avoid further heat input and possibly somewhat reduce phase interfacial area and solvent radiolytic damage. Operation can be restarted easily, without any needs for rework, by restarting heavy phase feed. It can be seen that process interruptions due e.g. to filled buffer tank and delay in clearance for further processing are relatively easily coped with and the main consequence is slight loss of plant throughput. Besides optimizing material production for LTAs, buffer tankage will provide adaptability for development purposes in allowing decoupled operation of separation areas. This supports process envelope trials, mal-operation tests, and investigations of new flow-sheets, etc. Flexibility in the coupling of buffer tanks will be valuable for longer trials.

There may be possibilities for further re-iterative, complementary, and synergistic development of flowsheet and main equipment selection and process structure. There appears to be a conceptual divergence between use of short residence time contactors, i.e. centrifugal, and long residence buffer tanks. With safety integral to design, the aim is to minimize process inventories of hazardous materials. Subject to GNEP non-proliferation needs, the potential should be explored for use of a chemical flow-sheet in which $\mathrm{Pu}$ is largely removed, e.g. $\geq 90 \%$, at an early process stage such that residual $\mathrm{Pu}$ level is comparable to or lower than the minor actinides, which in UREX+ are separated late in the process. This may reduce the need for and capital cost of substantial geometrically safe vessels and other equipment.

\section{III.F. Services}

Supporting services are required for AFCF and CFTC site infrastructures including administrative, analytical, cold process support (mockup \& testing), emergency response, engineering, environmental protection, health protection \& hygiene, human resources, procurement, and safeguards \& security. The process support systems and structures include deep bed filters, fan houses, stacks, cold feed and acid and water recovery units and stores for immobilized radioactive products, and by-products for UREX+, as given in section IIIB. Stores for wastes include capacity for GTCC compacted waste, LLW, and hazardous/mixed waste; including those from treatment of liquid wastes. A waste certification facility is also needed.

The AFCF HVAC system is based on a cascade air flow with three confinement zones and using no air recirculation. HVAC studies are planned regarding inert hot cell maintenance and equipment change-out strategy, sand filtration vs. HEPA filtration (e.g. footprint, filter proximity to cell, connecting tunnels, operations and D\&D costs), dedicated air supply to hot cells, and energy conservation. Analytical sampling, transfer to laboratory, and analysis is needed for process, MC\&A, and safety purposes. Pneumatic transfer systems are proposed for supply to a set of laboratories, including one for IAEA 
safeguards, dispersed around and serving the process functional areas. Modeling is needed to evaluate the impact of sampling and analysis turn around time (currently taken as $\leq 1$ day for liquids and $\leq 2$ days for solids), frequency, correlation with on-line measurement, laboratory location, etc., on sizing the analytical support areas, sample archiving, and the process surge capacity needed to await results. Emerging technologies to improve response and reduce waste and dose include micro-fluidic sampling and Lab-On-A-Chip. Regarding by-product storage, optimization of the high decay power Cs-Sr ceramic waste form, container, and storage environment is sought for prompt use of natural convection passively air cooled stores, not needing air filtration for the expected decay period of $\sim 300$ years. Both AFCF and CFTC EAS provide for extensive liquid LLW treatment and water recycle, including evaporation, UF, activated carbon, RO, and IX bed; CFTC EAS has $90 \%$ water recycle and 10\% discharge and AFCF, a smaller facility, has zero liquid discharge

\section{HISTORIC CAPITAL COST MAGNITUDE}

Cost is an essential issue in design. Next-generation, advanced aqueous reprocessing plants with more extensive separations are likely to have an increased scope compared to current commercial PUREX plants. Unless compelling technological breakthroughs can be identified, then it is reasonable to expect that current plant capital costs, at near maximum single line plant scale, will provide a likely lower bound cost magnitude. The extensive use of remote maintenance is likely to raise capital cost further, but may possibly lower overall unit processing cost by increasing capacity factor. From a systems view, increases in reprocessing cost may be offset by reduced waste management costs, including disposal. From a search of literature, a scatter chart was assembled of historical capital costs or design/cost study estimates (updated to 2005 money value [m.v.]) versus design throughput with a best fit line through the data points. The cost data spanned the period 1969-2005 and covered aqueous reprocessing plants. The approximate equation of the best fit line (23 points) is shown in Fig. 3.

$$
\text { Capital Cost }(\$ B, 2005 \text { m.v. })=2.7+1.8^{*} 10^{-3} \mathrm{t}(\mathrm{HM}) / \mathrm{a}
$$

For a $1,000 \mathrm{t}(\mathrm{HM}) / \mathrm{a}$ facility, the best-fit capital cost is approximately $\$ 4.5 \mathrm{~B}$ (2005 m.v.). But it was found that almost all values for the design/cost studies and for plants constructed, but not operated, lie below the best fit line. The total is 16 . The cost values for operating plants lie above the line. There are four values just above the line in the throughput range $600-900 \mathrm{t}(\mathrm{HM}) / \mathrm{a}$ - three of these, shown as circles, are the only PUREX oxide fuel reprocessing plants now operating in the world - France's UP-2 and UP-3, and U.K.'s THORP. The fourth value is an OECD cost exercise based closely on U.K. and French cost data from THORP, UP-2, and UP-3 in 1994 at the completion of plant construction. A fifth value well above

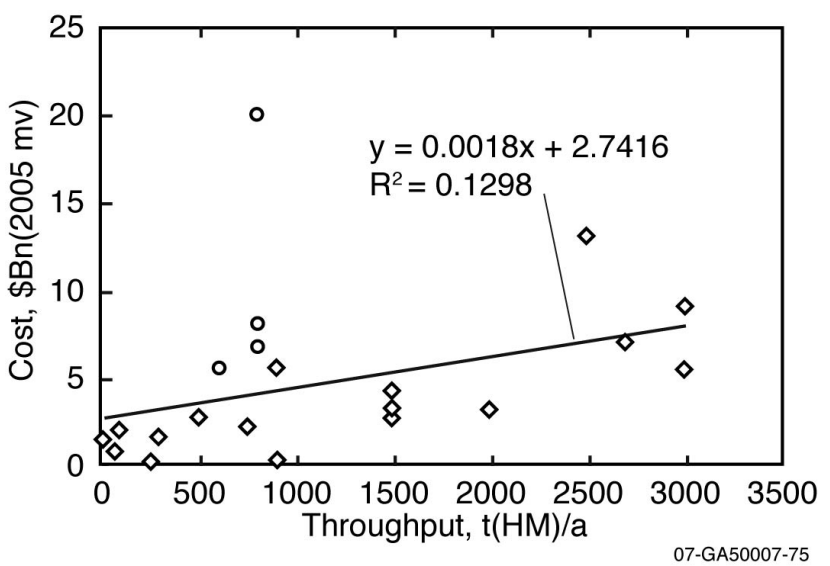

Fig. 3. Historic capital cost vs. throughput.

the best fit line is the 2,500 t(HM)/a French BCG COEX plant for U.S. irradiated LWR fuel, again based on operating La Hague and Melox technology. Although with economies of scale and know-how, this magnitude appears broadly consistent with other French capital costs based on UP-3 and UP-2-800 operating plant. There is an outlier value, shown as a circle, above the line, at $\$ 20 \mathrm{~B}$ and $800 \mathrm{t}(\mathrm{HM}) / \mathrm{a}$ for the Rokkasho plant expected to operate actively in 2008 . The final point, and the only one not based on current French/UK technology, is marginally above the best fit line, located at \$B 9.0 and $3,000 \mathrm{t}(\mathrm{HM}) / \mathrm{a}$ and corresponds to the "conservative" DuPont (SRS) canyon-based designs of the late 1970's. ${ }^{10}$ Except for the operating or near-operational French, British and Japanese PUREX oxide plants, few of these facilities were designed and/or built to today's standards and expectations for minimizing exposure to workers. It was also noted that the operating plants have capacity factors equivalent to $\sim 150-200$ full output days per year (d/a) while the design studies for plants not constructed often show values of 250-300 full output $d / a$.

The five French/UK PUREX technology points (UP-2-800, UP-3, THORP, OECD-NEA, and BCG COEX) give the best guide to modern reprocessing practice. The best fit line, though of poor statistical value, of Capital Cost French/UK PUREX is: \$B (2005 m.v.) = $3.6+3.7 \mathrm{t}(\mathrm{HM}) / \mathrm{a} / 1,000$ or for a $1,000 \mathrm{t}(\mathrm{HM}) / \mathrm{a}$ facility; the best-fit capital cost is $\sim \$ 7.3 \mathrm{~B}$ (2005 m.v.), which is $60 \%$ greater than historic best-fit line value.

\section{CONCLUSIONS}

1. The goals for the UREX+ process within the GNEP advanced fuel cycle differ considerably from the design requirements for the PUREX process but most of the 
unit operations and equipment comprising the conceptual design of UREX+ stem from state-of-theart technology for thermal and FR PUREX processing.

2. In general, the process objectives of the other national programs (Japan, France and R.F.) for the advanced fuel cycle (reprocessing) implement less partitioning steps and tend toward closer adherence to existing process logic and economic optimization.

3. Careful selection of processing cell type, size and design in conjunction with main process units, e.g. buffer tanks, contactors, and remote maintenance units, is desirable for CFTC LWR spent fuel separations to optimize capital, operating and decommissioning costs against daily rate, annual capacity and throughput risk.

4. Use of dynamic modeling is favored to seek the optimal operating strategy and plant design for UREX+ and potentially other flow-sheets having a series of independent separations and various specified products and process needs.

5. Subject to GNEP non-proliferation objectives, optimization of flow-sheets for early removal of most fissile material, may provide significant safety and cost advantages for commercial scale reprocessing plants, whilst easing adoption of engineered methods, such as geometric control, for criticality safety.

6. Capital costs of 23 current and historic aqueous reprocessing plants (actual data and design/cost studies) were examined and a cost correlation provided. Five PUREX technology data points give the best guide to modern reprocessing practice.

7. Due to increased scope and absent major breakthrough, advanced fuel cycle reprocessing plants are likely to have capital costs that lie above the historic best fit line, Fig. 3, and probably above an equation derived from five modern PUREX technology points.

\section{ACKNOWLEDGMENTS}

The authors gratefully acknowledge support and permission to publish from the U.S. Department of Energy. The authors also recognize technical participation by the INL co-located Center for Nuclear Systems Design and Analysis (CNSDA), which is an INL joint industry center co-sponsored by Burns and Roe Enterprises, Inc. (BREI) of Oradell, N.J. Thanks go to many staff within AFCF and CFTC EAS projects for their technical advice.

\section{REFERENCES}

1. Global Nuclear Energy Partnership Strategic Plan, GNEP-167312, Rev. 0, U.S. DOE, January 2007.

2. J.A. BUCKHAM, Status of USA reprocessing of highly radioactive fuels, IAEA Panel,Vienna, May, 1969.

3. M.S. OKAMOTO and M.C. THOMPSON, CoProcessing solvent extraction studies, Nuclear Technology, Vol. 43, pp. 126-131, 1979.
4. D.O. CAMPBELL and W.D. BURCH, Reprocessing Chem: Present Practices, Future Trends, J. Radioanalytical \& Nuclear Chem., Vol. 142. No.1, pp. 303-320, 1990. 5. M.F. DEBREUILLE et al., Reprocessing at La Hague: Industrial Experience and Perspectives, Global Conf., New Orleans, LA, USA, Nov, 2003.

6. Thermal Oxide Reprocessing Plant (THORP), Health \& Safety Executive, HM NII, UK, December 1995.

7. M. BENEDICT et al., Nuclear Chemical Engineering, Barnwell Fuel Plant, pp. 491-501, 2nd Ed. 1981.

8. G.L. RITTER et al., The Exxon Nuclear Fuel Recovery \& Recycling Center: Process, Facility, and Safety, Nucl. Technol., Vol. 43, pp. 194-221, MID-APR, 1979.

9. D.C. WITT, Liquid Waste Handling Facilities for a Conceptual LWR SNF Reprocessing Complex, Nucl. Technology, Vol. 43, pp. 244-58, MID-APR, 1979

10. M.J. HAIRE, Nuclear Fuel Reprocessing Costs, ANS Topical Meeting, Advances in Nuclear Fuel Management III, Hilton Head Island, S.C. Oct, 2003.

11. W.B. BOORE, SRS Historical experience with Fuel Reprocessing and Material Stabilization, Global Conference, New Orleans, LA, USA, Nov, 2003.

12. C.T. Kring and S.L. SCHROCK, Remote Maintenance "Lessons Learned" on Prototypical Equipment, ANS, Winter Meeting, Washington D.C., Nov, 1990.

13. J.V. DRAPER et al., Remote Maintenance Design Guide for Compact Processing Units, Oak Ridge National Laboratory, Report ORNL/TM-2000/124, August 2000.

14. T. WASHIYA et al., Development of a Centrifugal Contactor for FR Reprocessing, ATALANTE Conf. Scientific Research Back-End of Fuel Cycle, Oct, 2000.

15. Electrometallurgical Techniques for DOE Spent Fuel Treatment, Final Report, National Academy Press, Washington, D.C. U.S.A., 2000.

16. C. PEREIRA et al., Lab-scale Demonstration of the UREX+2 Process, WM'05 Conference, Tucson, AZ, February 27 - March 3, 2005.

17. R.A. WIGELAND et al., Separations Criteria to Improve Utilization of a Geologic Repository, Nuclear Technology, Vol. 45, pp. 95-106, 2006.

18. Phase II Final Report; Feasibility Study on Commercial FR Cycle Systems, JAEA and JAPC, March 2006.

19. French R\&D on P\&T of Long-lived Radionuclides, Review of 2005 CEA Report, OECD-NEA, \# 6210,Report No. 2006.

20. P. PRADEL and C. COURTOIS, French Fuel Cycle Strategy and P\&T Program, OECD-NEA, 9th Inf. Exchange Meeting on P\&T, Nimes, Sept 2006.

21. J-M. ADNET, Development of New Hydrometallurgical Process: GANEX Concept, Global Conference, Paper \#119, Tsukuba, Japan, Oct. 2005.

22. A.V. BYCHKOV, Closed Fuel Cycle Strategies and National Programs in RF, OECD-NEA, 9th Inf. Exchange Meeting on P\&T, Nimes, Sept. 2006.

23. A.F. GRATCHYOV et al., Experiment of 3 BN-600 MOX Vibropac FAs Irradiation, Paper \#583, Ibid Ref. 21. 